This item was submitted to Loughborough's Research Repository by the author.

Items in Figshare are protected by copyright, with all rights reserved, unless otherwise indicated.

\title{
Dynamic response of thermally bonded bicomponent fibre nonwovens
}

PLEASE CITE THE PUBLISHED VERSION

http://www.ttp.net/1660-9336.html

\section{PUBLISHER}

(c) Trans Tech Publications Inc.

\section{VERSION}

AM (Accepted Manuscript)

\section{LICENCE}

CC BY-NC-ND 4.0

\section{REPOSITORY RECORD}

Demirci, Emrah, Memis Acar, Behnam Pourdeyhimi, and Vadim V. Silberschmidt. 2019. "Dynamic Response of Thermally Bonded Bicomponent Fibre Nonwovens". figshare. https://hdl.handle.net/2134/8736. 
This item was submitted to Loughborough's Institutional Repository (https://dspace.lboro.ac.uk/) by the author and is made available under the following Creative Commons Licence conditions.

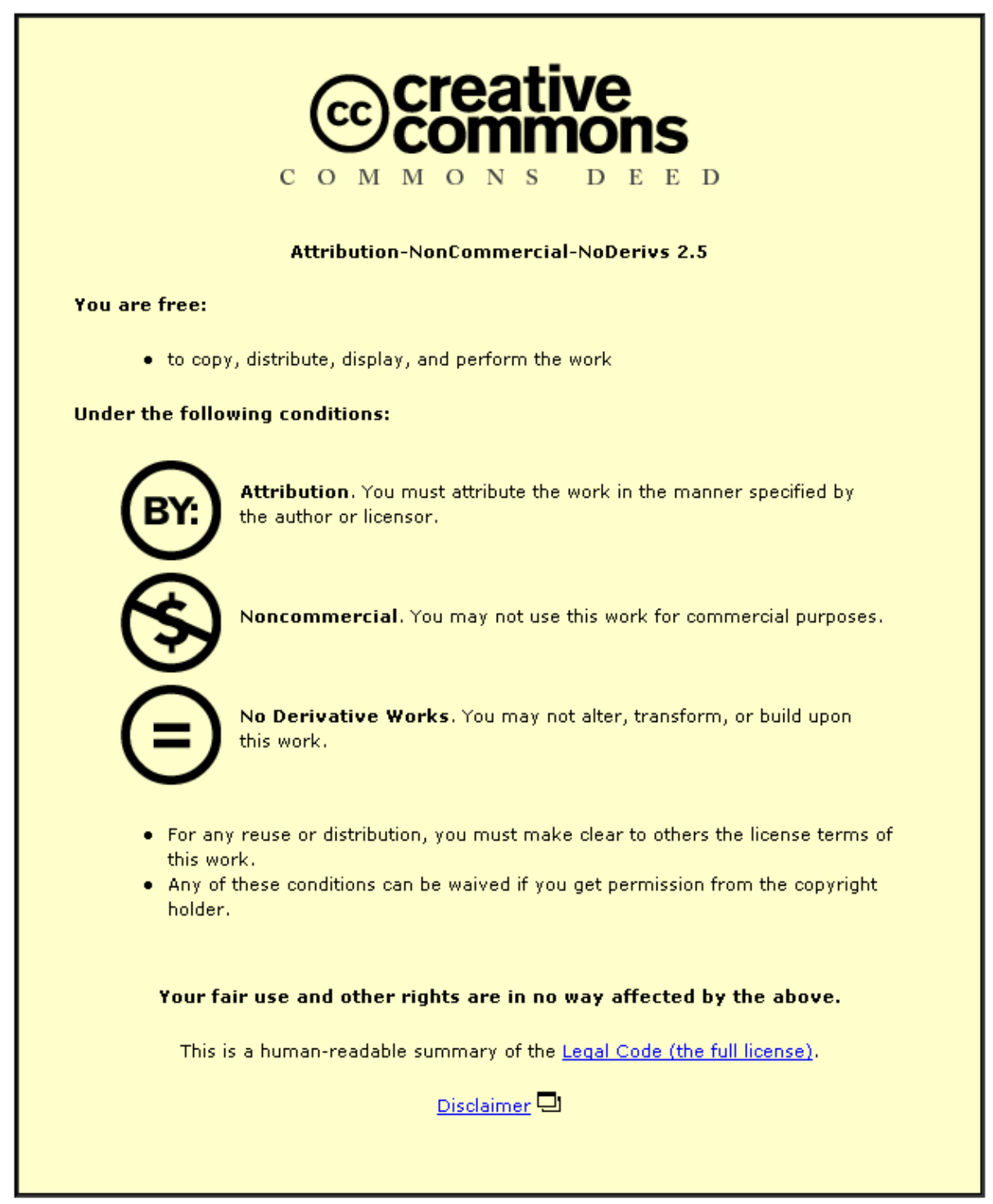

For the full text of this licence, please go to: http://creativecommons.org/licenses/by-nc-nd/2.5/ 


\title{
Dynamic Response of Thermally Bonded Bicomponent Fibre Nonwovens
}

\author{
Emrah Demirci ${ }^{1, a}$, Memiş Acar ${ }^{1, b}$, Behnam Pourdeyhimi ${ }^{2, \mathrm{c}}$ and Vadim V. \\ Silberschmidt, ${ }^{1,}$ \\ ${ }^{1}$ Wolfson School of Mechanical and Manufacturing Engineering, Loughborough University, UK, \\ ${ }^{2}$ Nonwovens Cooperative Research Center, North Carolina State University, USA \\ ae-mail: e.demirci@lboro.ac.uk \\ be-mail:m.acar@lboro.ac.uk \\ ce-mail: behnam pourdeyhimi@ncsu.edu \\ de-mail: v.silberschmidt@lboro.ac.uk
}

Keywords: nonwoven, orientation distribution function, bicomponent fibre, finite element, anisotropy, composite material, dynamic response

Having a unique microstructure, nonwoven fabrics possess distinct mechanical properties, dissimilar to those of woven fabrics and composites. This paper aims to introduce a methodology for simulating a dynamic response of core/sheath-type thermally bonded bicomponent fibre nonwovens. The simulated nonwoven fabric is treated as an assembly of two regions with distinct mechanical properties. One region - the fibre matrix - is composed of non-uniformly oriented core/sheath fibres acting as link between bond points. Non-uniform orientation of individual fibres is introduced into the model in terms of the orientation distribution function in order to calculate the structure's anisotropy. Another region - bond points - is treated in simulations as a deformable bicomponent composite material, composed of the sheath material as its matrix and the core material as reinforcing fibres with random orientations. Time-dependent anisotropic mechanical properties of these regions are assessed based on fibre characteristics and manufacturing parameters such as the planar density, core/sheath ratio, fibre diameter etc. Having distinct anisotropic mechanical properties for two regions, dynamic response of the fabric is modelled in the finite element software with shell elements with thicknesses identical to those of the bond points and fibre matrix.

\section{Introduction}

Nonwovens are polymer-based engineered textiles having randomly distributed fibres bonded together with mechanical, thermal or chemical techniques. This paper focuses on thermally bonded nonwoven fabrics with bicomponent fibres made of polymers. Such fibres have a core/sheath structure, with a material of the inner region - core - having a higher melting temperature than that of the outer region (sheath). During the bonding of these fibres, a hot calender with an engraved pattern presses the fibre web causing the sheath part of the fibres to melt and providing the desired bonding between the fibres while the fibres' core part remains fully intact. As a result of the bonding process, two distinct regions, namely bond points and the fibre matrix, possessing different characteristics, collectively form the nonwoven fabric. The structure of the resulting thermally bonded bicomponent fibre nonwoven is shown in Fig. 1 obtained with scanning electron microscopy (SEM).

Having two distinct regions with different characteristics, thermally bonded bicomponent fibres exhibit a unique deformation behaviour. The deformation behaviour of thermally bonded bicomponent fibre nonwovens is complicated due to the fact that non-uniform fibrous structure leads to their anisotropy $[1,3]$ while polymer-based constituents are characterised by a temperaturedependent large-strain elastic-plastic behaviour including viscous effects [4]. Several studies were 
performed to predict the mechanical response of such materials regarding fibre arrangements [5], curliness of the fibres [6], orientation distribution of fibres [7, 8] and bonding temperature [9]. However, those studies offered only partial solutions for prediction of the mechanical response of such materials to loading regardless of dynamic effects related to time-dependent deformation mechanisms. This paper aims to introduce a practical way of simulating the dynamic mechanical behaviour of thermally bonded nonwoven fabrics in 3D, which could be used in product development and optimization.

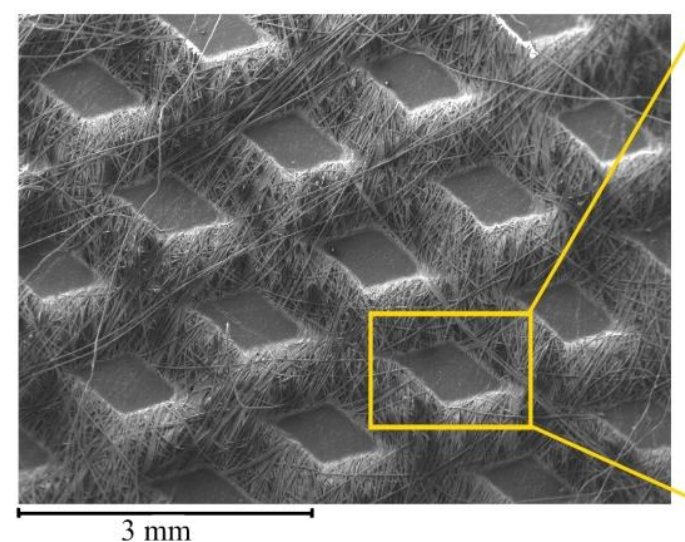

$3 \mathrm{~mm}$

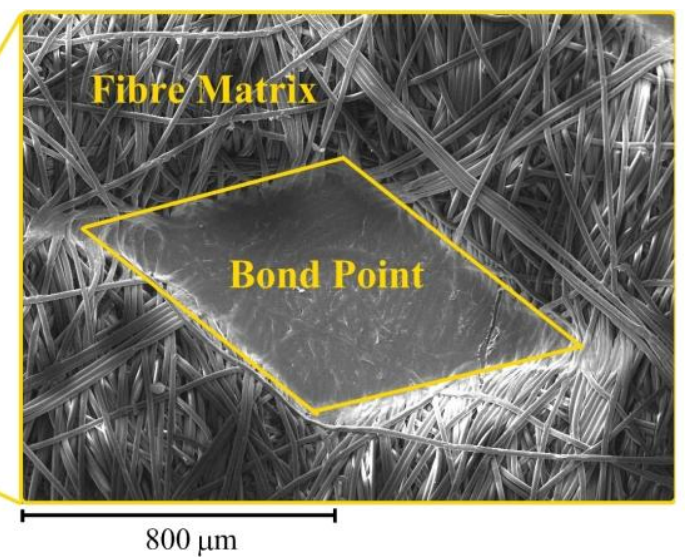

Fig. 1. SEM images with different magnification of bicomponent fibre nonwoven fabric (planar density: $150 \mathrm{~g} / \mathrm{m}^{2}$ fibre: 75/25 PA6/PE) composed of bond points and fibre matrix

\section{Assessment of Mechanical Properties}

The main reason of distinct mechanical properties of two regions (bond points and fibre matrix) of nonwoven materials is the difference in their microstructures. Bond points are solid and continuous structures whereas the fibre matrix is porous and compressible (Fig. 2). Besides, due to random orientation of fibres, the mechanical behaviour of these regions is anisotropic $[1,10]$. Therefore, direction-dependent mechanical properties of these regions should be assessed separately.

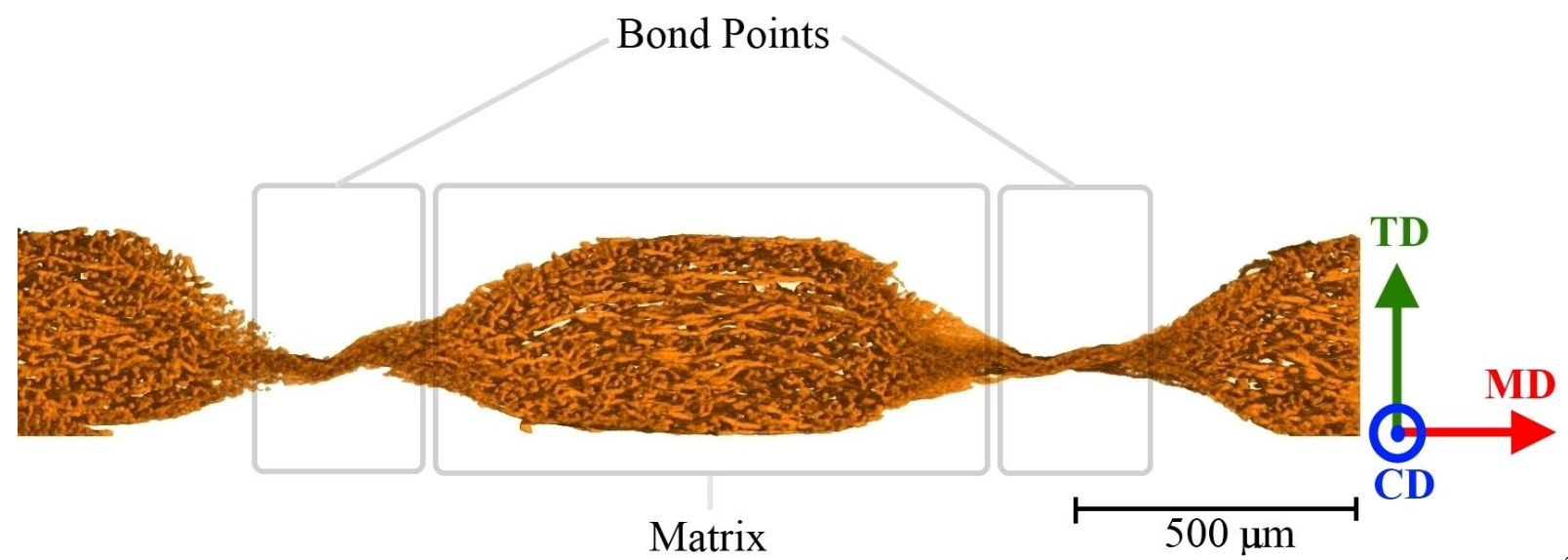

Fig. 2. Through-thickness image of thermally bonded nonwoven fabric (planar density: $150 \mathrm{~g} / \mathrm{m}^{2}$ fibre: 75/25 PP/PE) obtained with X-ray micro computed tomography (CT)

The procedure for assessing the mechanical properties of bond points and the fibre matrix starts with computing the level of mechanical anisotropy in the structure. The level of direction dependendency of the mechanical response is crucial for adequate simulations. As the number of material symmetry planes decreases, the amount of parameters defining the directional behaviour increases signifantly, hence increasing the complexity and computation time. Orthotropy, having 
three symmetry planes, can sufficiently define the level of anisotropy for thermally bonded nonwovens, having three principal directions, namely, machine direction (MD), cross direction (CD) and thickness direction (TD). MD is the flow direction of the nonwoven fibres on the conveyor during manufacturing, $\mathrm{CD}$ is perpendicular to MD in the plane of fabric and TD is normal to this plane (Fig. 2). The principal directions of orthotopy can be assumed as coincident with the principal directions of nonwovens for the definition of the mechanical properties A numerical relation between orientation distribution function (ODF) of fibres and mechanical anisotropy of nonwoven material is introduced and verified experimentally in [11]. With the software Nonwovens Anisotropy V1 - described in [11], orthotropic constants defining the direction dependency of mechanical properties of regions of a nonwoven are determined using SEM or X-ray micro CT image of their fibre matrix (Fig. 3). The software is facilitated in several studies [12, 13] for determining the orientation distribution function of fibres, which represents the level of randomness of fibre orientations in the nonwoven fabric.

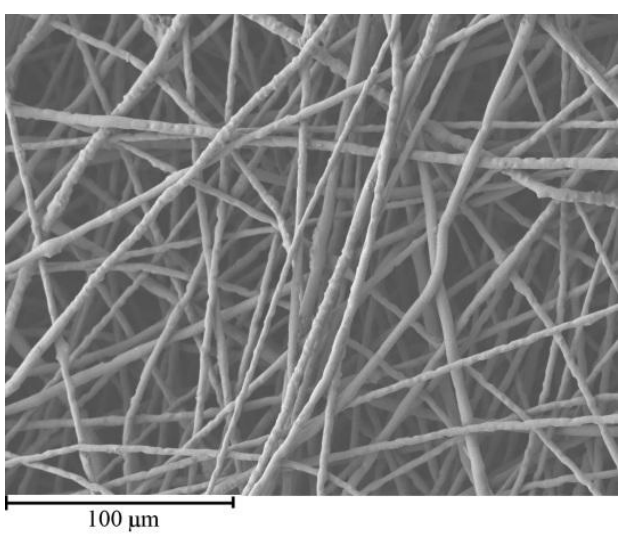

(a)

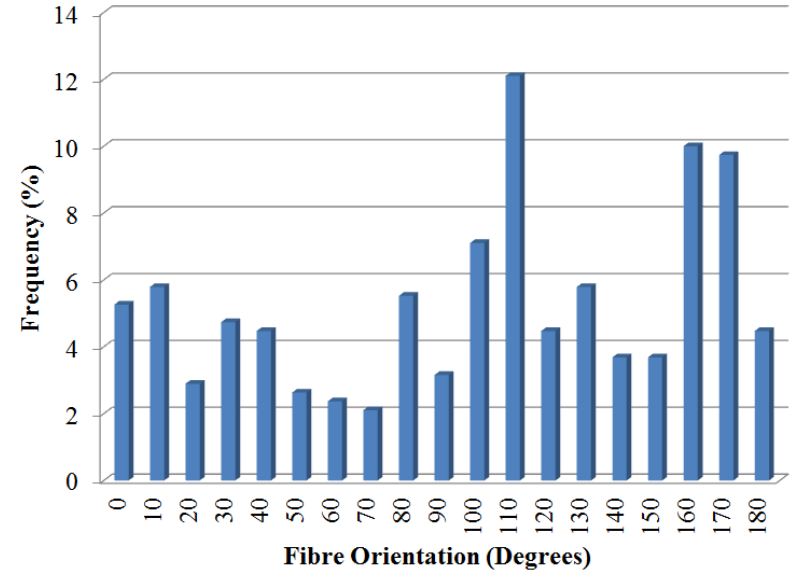

(b)

Fig. 3. SEM image of fibre matrix of nonwoven (planar density: $50 \mathrm{~g} / \mathrm{m}^{2}$ fibre: $75 / 25 \mathrm{PP} / \mathrm{PE}$ ) (a) and corresponding ODF (b) computed with Nonwovens Anisotropy V1 [11]

After computing the orthotropic constants, the orthotropic elastic, plastic and viscous mechanical properties of bond points and fibre matrix regions are assessed using the manufacturing parameters of the nonwoven fabric and the mechanical properties of a constituting single fibre [14]. In order to calculate these properties, several schemes are facilitated, such as the Rule of Mixtures (RoM), for computing the mechanical properties of bond points and the fibre matrix. Elastic moduli and flow curves in MD and CD are obtained based on the RoM equation as

$$
\sigma=\sigma^{A} V^{A}+\sigma^{B} V^{B}
$$

where $\sigma$ is the resultant flow stress (resultant modulus of elasticity); $\sigma^{A, B}$ are the flow stresses (elastic moduli) and $V^{A, B}$ are volumetric fractions of materials $\mathrm{A}$ and $\mathrm{B}$, respectively. Dynamic parameters are determined with normalizing the time-dependent behaviour of single fibres used to manufacture the fabric [14]. Fig. 4 demonstrates tensile relaxation moduli of bond points and the fibre matrix, which are used to characterise time-dependent behaviour of numerical model in the finite element (FE) software. 


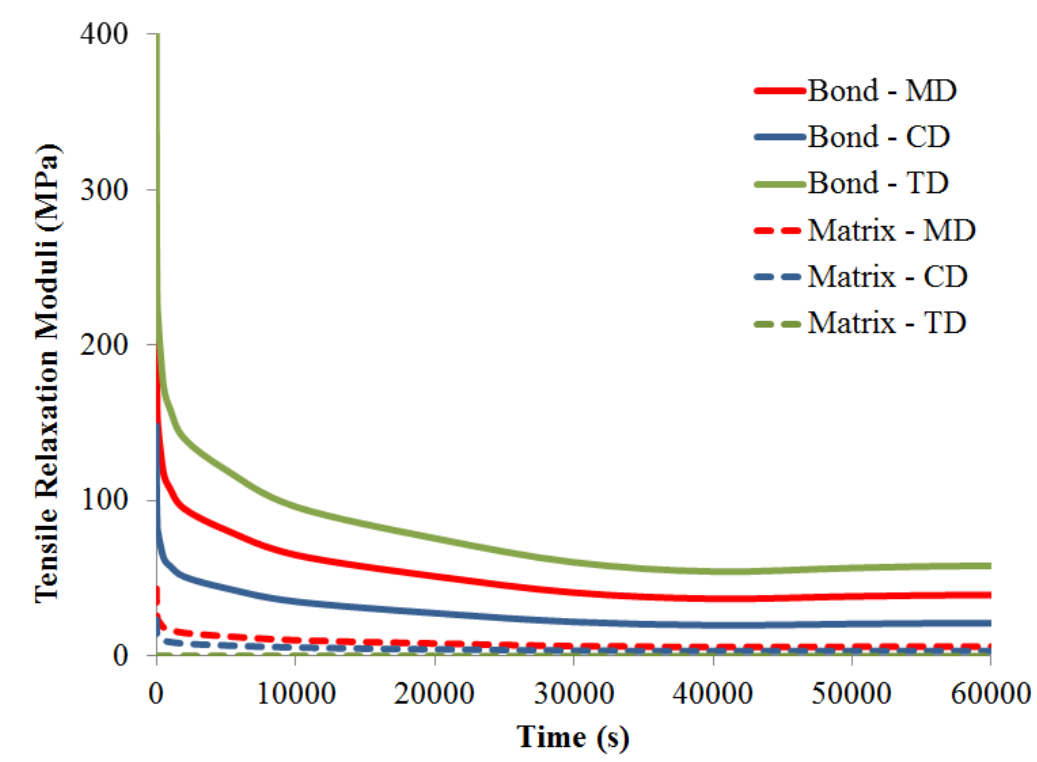

Fig. 4. Tensile relaxation moduli of bond points and fibre matrix constituting numerical model of thermally bonded bicomponent fibre nonwoven

\section{Finite Element Model}

The obtained parameters are used to characterize orthotropic viscoelastic-plastic mechanical properties of bond points and fibre matrix in the FE model. The tensile tests are performed on 50 $\mathrm{g} / \mathrm{m}^{2}$ bicomponent fibre thermally bonded nonwoven specimens of $30 \mathrm{~mm}$ x $15 \mathrm{~mm}$ in size along $\mathrm{MD}$ and $\mathrm{CD}$, respectively, to verify the developed FE model. To compare the obtained FE results, a force-displacement curve, measured in real-life tests, is calculated based on computed stresses.

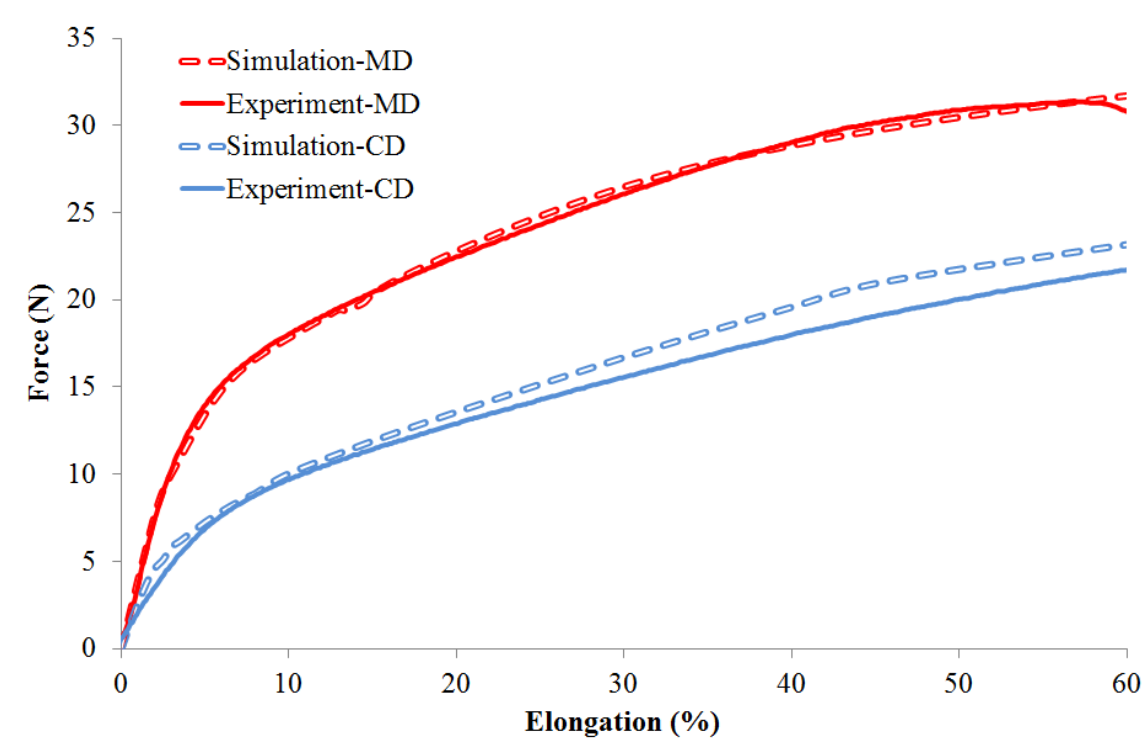

(a)

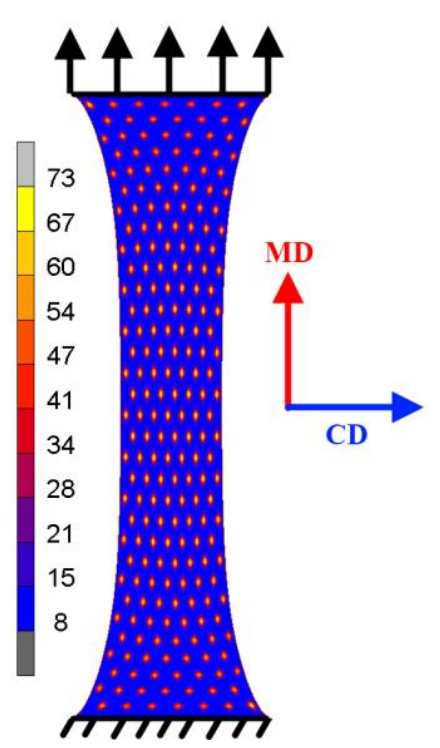

(b)

Fig. 5. Force-extension curves from tensile tests and FE simulations in MD and CD for $50 \mathrm{~g} / \mathrm{m}^{2}$ thermally bonded bicomponent fibre nonwovens (a) and FE model showing equivalent von Mises stress in (MPa) distribution at $60 \%$ extension (b)

Due to a stiffer structure of thin bond points, stresses are more concentrated in these regions (Fig. 5b). On the other hand, their deformation is less than that of matrix reflecting the real-life response leading to failure of matrix before failure of bond points in tension. As obvious from Fig. 5a, FE simulation results and the experimental data are in good agreement. The slight deviation of 
the numerical results from experimental ones can be explained by the effect of several secondary factors not accounted for in the model. Among them are the curliness of the fibres, inter-fibre friction in the matrix region, etc. Apparently, the input data such as the flow curve of a single fibre is crucial, providing an average stress-strain curve for the fibres composing the nonwoven fabric. Despite some possible sources of deviation, the FE model successfully reproduces the dynamic response of the nonwoven specimens to tensional load.

\section{Conclusions}

A practical way of simulating real-life deformation behaviour of thermally bonded bicomponent fibre nonwovens is introduced in this study. The procedure for generating the numerical model of nonwovens is straight-forward and consists of two main parts: assessment of mechanical properties and FE modelling. The numerical model proposed in this study is effective in predicting the real deformation characteristics of thermally bonded nonwovens including time effects. This model can eliminate time consuming and costly trial - and - error based product development and optimization stages. Besides, the model can be implemented in any commercial FE software package capable of implementing orthotropic viscoelastoplasticity.

\section{Acknowledgement}

The authors gratefully acknowledge the support of Nonwovens Cooperative Research Center, North Carolina State University, USA.

\section{References}

[1] E. Demirci, M. Acar, B. Pourdeyhimi and V.V. Silberschmidt: Computational Materials Science Vol. 50 (4) (2010), p. 1286

[2] S. Michielsen, B. Pourdeyhimi and P. Desai: Journal of Applied Polymer Science Vol. 99 (2006), p. 2489

[3] H. S. Kim: Fibers and Polymers Vol. 5 (3) (2004), p. 177

[4] H.S. Kim, B. Pourdeyhimi, A.S. Abhiraman and P. Desai: Textile Research Journal Vol. 72 (7) (2002), p. 645

[5] S. Adanur and T. Liao: Textile Research Journal Vol. 69 (11) (1999), p. 816

[6] A. Rawal: Journal of Industrial Textiles Vol. 36 (2) (2006), p. 133

[7] H. S. Kim and B. Pourdeyhimi: Journal of Textile and Apparel, Technology and Management Vol. 1 (4) (2001), p. 1

[8] H.S. Kim: Fiber and Polymers Vol. 5(2) (2004), p. 139

[9] G.S. Bhat, P.K. Jangala and J.E. Spruiell: Journal of Applied Polymer Science Vol. 92 (2004), p. 3593

[10] X. Hou, M. Acar and V.V. Silberschmidt: Computational Materials Science Vol. 46 (3) (2009), p. 700

[11] E. Demirci, M. Acar, B. Pourdeyhimi and V.V. Silberschmidt: Computational Materials Science (2011), http://dx.doi.org/10.1016/j.commatsci.2011.01.033

[12] B. Sabuncuoglu, M. Acar and V.V. Silberschmidt: Computational Materials Science (2011), http://dx.doi.org/10.1016/j.commatsci.2010.12.005 
[13] X. Hou, M. Acar and V.V. Silberschmidt: Computational Materials Science Vol. 50 (4) (2010), p. 1292

[14] E. Demirci, M. Acar, B. Pourdeyhimi and V.V. Silberschmidt:, "Anisotropic Elastic-Plastic Mechanical Properties of Thermally Bonded Bicomponent Fibre Nonwovens", ASME $201010^{\text {th }}$ Biennial Conference on Engineering Systems Design and Analysis (ESDA 2010), Istanbul, Turkey, 12-14 July 2010. 